\title{
Modeling of Nutrients Removal in Lab Scale Ecosystem using Aquatox
}

\author{
S.Vanithaand C.Sivapragasam
}

\begin{abstract}
Paper Protection and restoration of water resources is a major challenging task in recent past. In this study, ability of Aquatox in predicting small scale aquatic ecosystem is studied with limited data. For this purpose experimental pond is created with and without macrophyte duckweed. The Root Mean Square Error (RMSE) is used as performance measure for simulated and experimental values. The phosphate and ammonia concentrations are well predicted while the prediction of nitrate is not encouraging which may require some additional parameters in this model for prediction. After introducing detritus (sediment) as input parameter, RMSE decreases and it is confirmed that sediments parameter improve the model prediction. This suggests special attention is to be given for selection of input parameters in small lab scale aquatic ecosystem.
\end{abstract}

Keywords : pond water, duckweed, Aquatox, detritus.

\section{INTRODUCTION}

Anthropogenic activities are increasing day by day due to urbanization, industrialization and human development. Today, environmental management programs have a mandatory task to reduce the damages occurring to the water resources by proper protection of the aquatic ecosystems. Eutrophication and contamination with micro pollutants are the major root causes for the lakes and rivers in water quality management system in the past decades[1].

Eutrophication increases primary productivity in lakes [2]. The amount of pollution in a lake increases with lack of treatmentandadditionalinputofanthropogenicactivities[3]. At present, there is a growing interest for the use of ecological models to improve the ecological risk assessment (ERA) of the toxic pollutants [4]. Ecological model Aquatox is a general ecological risk assessment model which evaluates the past, present, future direct and indirect effects from various stressors including nutrients, organic wastes, sediments, toxic organic chemicals, flow and temperature in aquatic ecosystem[5,6].

Reference [7] applied Aquatox successfully to simulate the water quality of aquatic systems especially in terms of dissolved oxygen and Biochemical Oxygen Demand. [8] used Aquatox to develop nutrient criteria that requires less aquatic and biological monitoring data than an empirical

Revised Manuscript Received on December 05, 2019.

*Dr.S.Vanitha, department of Civil Engineering, Kalasalingam Academy of Research and Education, Krishnankoil, India. Email:svanithacivil@gmail.com.

Dr.C.Sivapragasam*,Center of water technology, department of Civil Engineering, Kalasalingam Academy of Research and Education, Krishnan kovil, Tamilnadu, India..Email: sivapragasam@klu.ac.in approach i.e. relatively minimal data is used in conjunction with a linked mechanistic modeling system that includes a watershed model and an ecological effects model. [9] used this model to provide an understanding of food web dynamics, characterization of bioaccumulation and identification of most sensitive ecosystem components.

An Aquatox model describes an ecosystem through a set of predefined inputs. All the reported works on Aquatox demonstrate a data intensive application. However, in many situations not all the inputs are either used or are available concerning an ecosystem. The accuracy of Aquatox simulation very much depends on necessary and useful inputs. In this study an attempt is made to simulate water quality using Aquatox with only initial water quality parameters as inputs. The performance of Aquatox simulation under limited data is assessed and conclusions are drawn on effectiveness of such modeling under limited inputscenario.

\section{METHODOLOGY}

\section{ARTIFICIAL PONDS SIMULATION}

The pond water is collected from Mariyan Oorani which is located at Sattur, Tamilnadu and two batch scale setups are made each with a diameter of $0.3 \mathrm{~m}$. In case study $1,0.3 \mathrm{~m}$ diameter container is filled with pond water of 15 liters as initial volume. In case study 2, macrophyte duckweed (15 gm wet weight) is introduced in 15 litres pond water sample. Duckweed is a member of the Lamnacae family of floating plants that grow fast and spread quickly [10]. The collected water sample is analyzed for water quality parameters namely dissolved oxygen, carbon dioxide, phosphate, nitrate, ammonia, $\mathrm{pH}$, temperature and water depth which are used as input parameters in Aquatox model. $\mathrm{pH}$ is measured using $\mathrm{pH}$ electrode method, dissolved oxygen is measured using winklers method, temperature using thermometer, ammonia and carbon dioxide using volumetric titration, phosphate using ammonium molybdate method and nitrate using stannous chloride method using Systronics make. Experiments are conducted every day. The above two artificial pond samples are tested for duration of sixdays. Fig 1 shows laboratory scale experimental setup of artificial ecosystem.

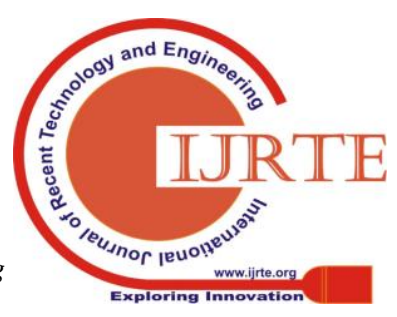




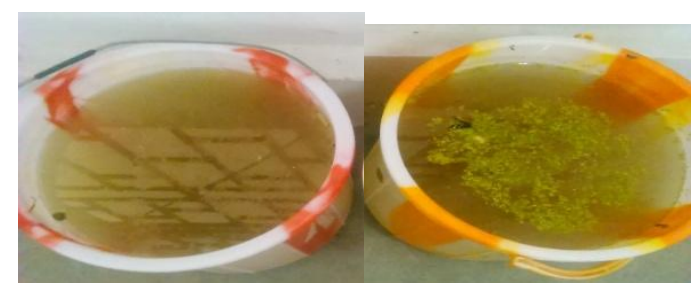

Fig 1. Experimental setup of artificial ecosystem in lab scale

Error measurement is used for this study is Root Mean Square equation which is given by

$$
R M S E=\sqrt{\left.\frac{1}{n} \sum_{i=1}^{n}\left[\left(X_{m}\right)_{i}\right]-\left(X_{s}\right)_{i}\right]^{2}}
$$

\section{AQUATOX}

This software was developed by the United States Environmental Protection Agency (USEPA) [6]. It is an important environmental modeling software and from this model, the combined effects of the entire ecosystem including fate and characteristics of various pollutants such as aquatic plants, fish and invertebrates and its various effects on the ecosystem can be predicted. This software is applied for the observation of the cause and effect relationships among chemical water quality, physical environment as well as aquatic life. Also, the data on several state variables like plants, detritus, fishes, toxic chemicals, $\mathrm{pH}$, temperature, volume, wind etc can be provided as input to this software. The default values of almost all biological input parameters like plants, animals and fishes are available in the Aquatox library and they can also be taken as user defined. Aquatox uses a very efficient fourth- and fifth- order Runge-Kutta integration routine with adaptive step size to solve the differential equations [11]. Direct and indirect effects of temperature and other factors like nutrients, chemicals etc are taken into account within the model. The Aquatox release 3.1 beta is used for this study. Only initial day water quality parameters are tested in laboratory are introduced in Aquatox.

In first case study dissolved oxygen, nitrates, phosphates, ammonia, carbon dioxide, water depth, temperature are introduced as inputs, In second case study, dissolved oxygen, nitrates, phosphates, ammonia, carbon dioxide, water depth, temperature and ash free dry weight (dry weight of duckweed) are introduced.

\section{BIOLOGICAL DATA ANALYSIS}

The AFDW-Ash free dry weight of duckweed is initially calculated with standard procedure and was found by drying $15 \mathrm{~g}$ of duckweed in oven for 1 hour at $60^{\circ} \mathrm{C}$ and then superheating in muffle furnace at $300^{\circ} \mathrm{C}$ for 3 to 4 hours $(7.08 \mathrm{~g} / \mathrm{m} 2$ dry weight of duckweed). This is also one of the input parameter introduced in Aquatox for case study 2.

\section{RESULT ANDDISCUSSIONS}

The models are run with initial observations. Predicted values for six days are taken from Aquatox. Predicted data from Aquatox are compared with actually observed data tested in laboratory. Table 1 shows the RMSE of two case studies

before introducing detritus. There is a good correlation obtained between predicted and observed data for ammonia in both case studies, while for nitrate correlation between observed and predicted results are weak. Fig. 23 and 4 show the graphs depicting comparison between observed and predicted values for phosphate, nitrate and ammonia with and without duckweed.

In this graph, blue data points are represented as observed data points and red points are taken for giving the $45^{\circ}$ line.

In this trail the simulation is conducted without introducing the effect of sediments(detritus). In the next trial, detritus details are introduced in both these case studies [labile detritus (50 g/m2 dry)], [refractory detritus ( $50 \mathrm{~g} / \mathrm{m} 2$ dry)], in addition to existing input parameters. Table 2 shows the RMSE of the two case studies after introducing detritus. It is found that the predicted results are significantly improved with addition of detritus as the additional input parameter. Fig. 5,6 and 7 show the graphs depicting comparison betweenobserved and predicted values for phosphate, nitrate and ammonia with and without duckweed after introducing detritus. The presence of detritus improves nitrate modeling in both cases as reflected by decrease in RMSE from 28 to 23 . Although the RMSE is still on the higher side, a closer analysis revealed that the model simulated the observed data more accurately for both the case studies in the first two days after which the prediction was not that accurate. Similar results are observed for phosphate. Prediction of ammonia is slightly affected after introducing detritus.

From an overall analysis, it is seen that under limited data set, Aquatox predicted well for ammonia and phosphate while nitrate is not. This indicates that in the functioning of this simple ecosystem, there are other relevant parameters that need to be introduced for the model to have an overall meaningful simulation. Further, since this is a lab scale study, the ecosystem created is not truly reflective of the real ecosystem in the field. The results indicate that Aquatox modeling should be used with caution in lab scalestudies.

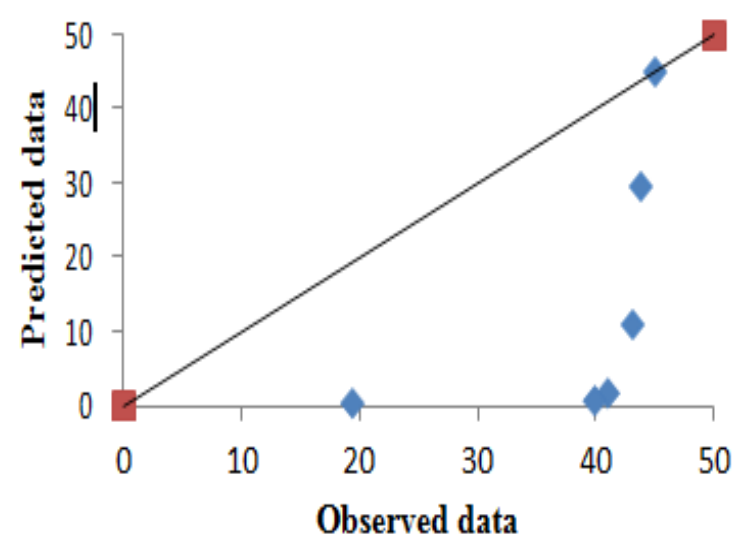

Fig.2(a). Comparison of observed data and predicted data for nitrate (case study 1) 


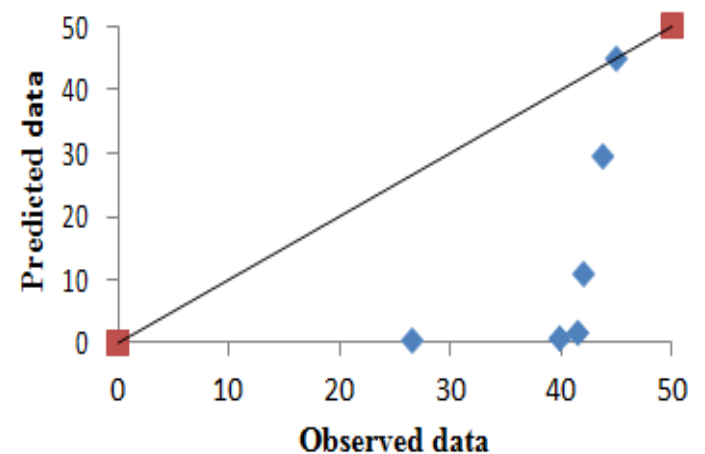

Fig.2(b). Comparison of observed data and predicted data for nitrate (case study 2)

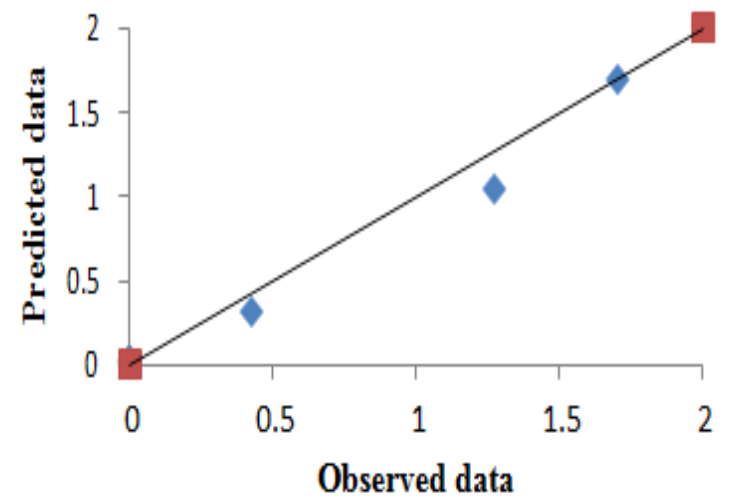

Fig.3(a). Comparison of observed data and predicted data for ammonia (case study 1)

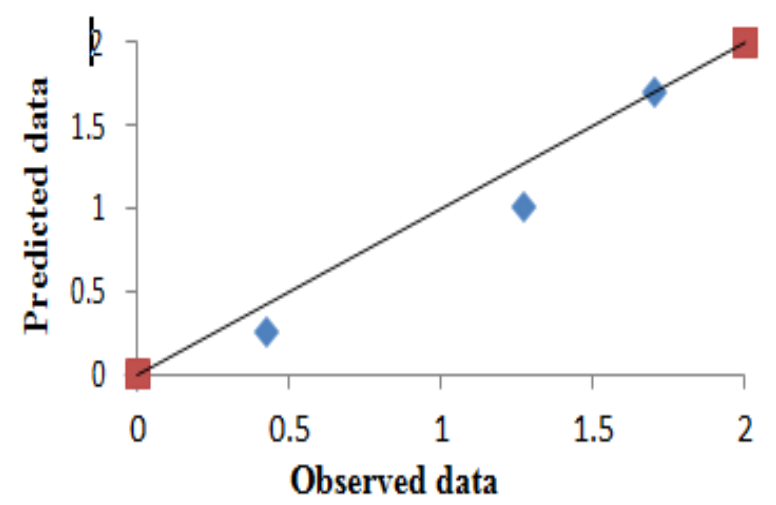

Fig.3(b). Comparison of observed data and predicted data for ammonia (case study 2)

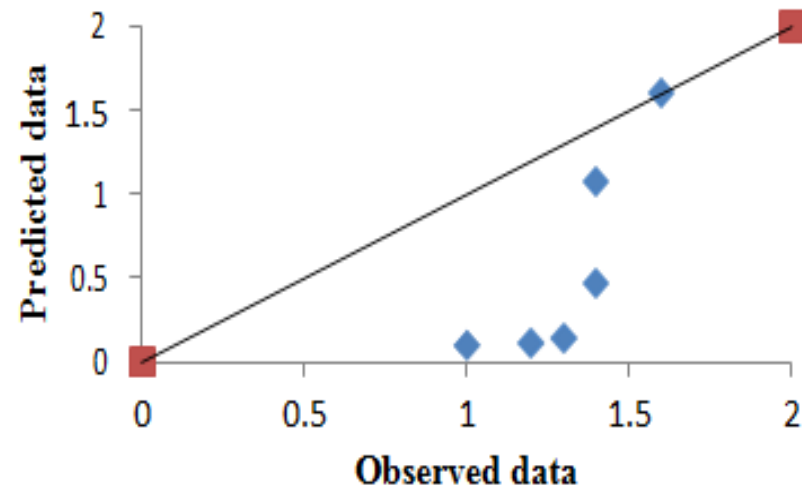

Fig.4(a). Comparison of observed data and predicted data for phosphate (case study 1)

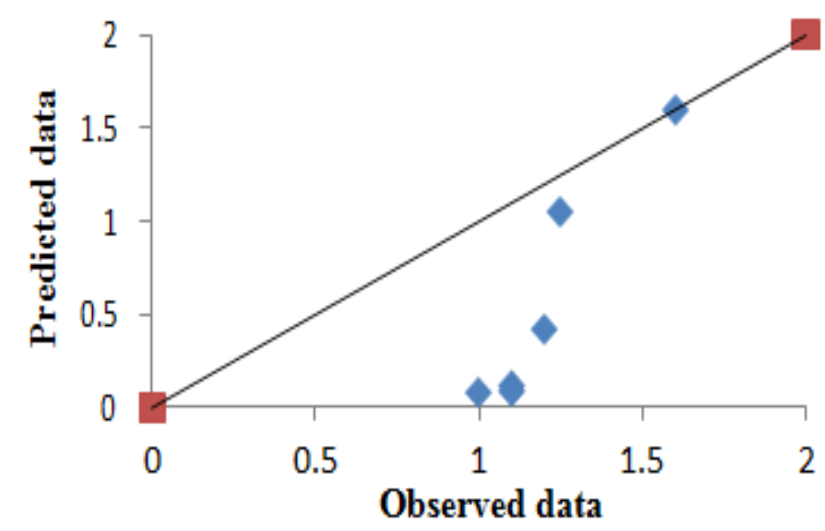

Fig.4(b). Comparison of observed data and predicted data for phosphate (case study 2)

Table I-: RMSE of Different Case Studies Before Introducing Detritus

\begin{tabular}{|l|l|l|}
\hline $\begin{array}{l}\text { Water } \\
\text { quality } \\
\text { paramete } \\
\text { rs }\end{array}$ & \multicolumn{2}{|l|}{ Without detritus(mg/l) } \\
\hline Nitrate & 27.88 & 28.86 \\
\hline Ammonia & 0.104 & 0.128 \\
\hline Phosphate & 0.85 & 0.76 \\
\hline
\end{tabular}

Table II-: RMSE of Different Case Studies After Introducing Detritus

\begin{tabular}{|c|c|c|}
\hline \multirow{2}{*}{$\begin{array}{l}\text { Water } \\
\text { quality } \\
\text { parameters }\end{array}$} & \multicolumn{2}{|c|}{$\begin{array}{l}\text { After introducing detritus } \\
\text { parameter(mg/l) }\end{array}$} \\
\hline & Case study & Case study 2 \\
\hline Nitrate & 23.90 & 23.68 \\
\hline Ammonia & 2.17 & 2.015 \\
\hline Phosphate & 0.628 & 0.699 \\
\hline
\end{tabular}




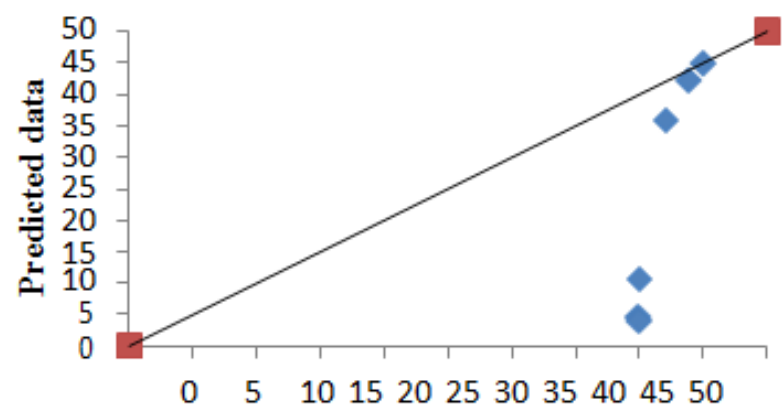

Observed data

Fig.5(a). Comparison of observed data and predicted data for nitrate after introducing detritus (case study 1)

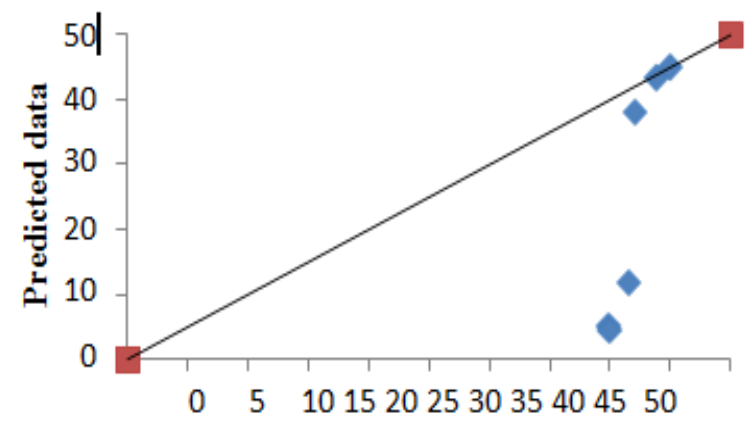

Observed data

Fig.5(b). Comparison of observed data and predicted data for nitrate after introducing detritus (case study 2)

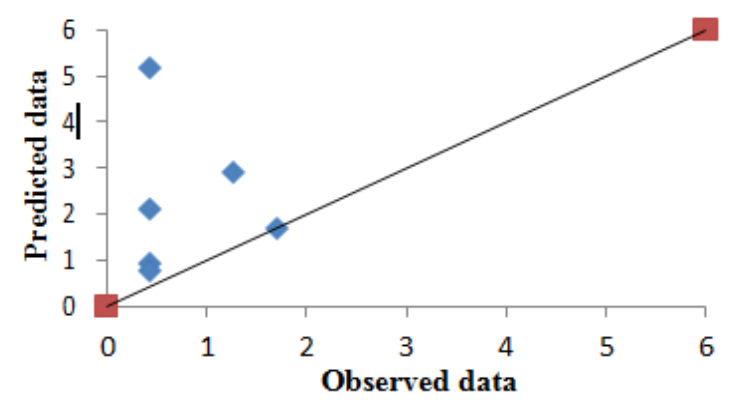

Fig.6(a). Comparison of observed data and predicted data for ammonia after introducing detritus (case study 1)

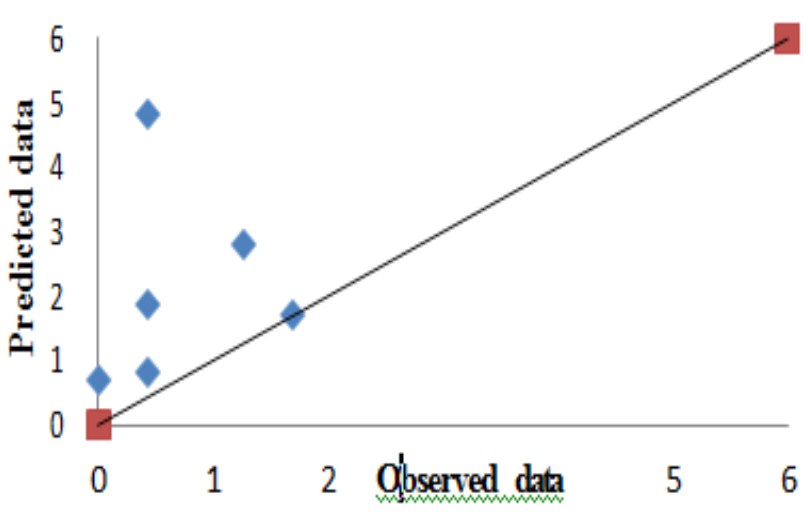

Fig.6(b). Comparison of observed data and predicted data for ammonia after introducing detritus (case study2)

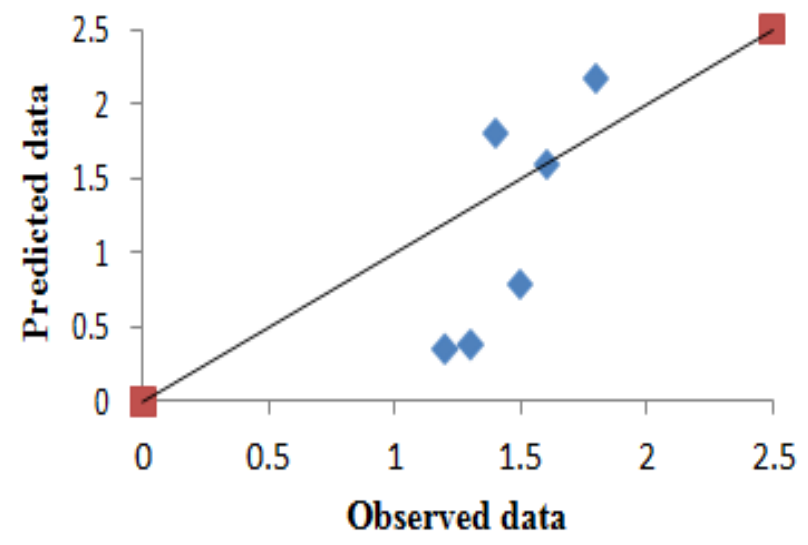

Fig.7(a). comparison of observed data and predicted data for phoshate after introducing detritus (case study1)

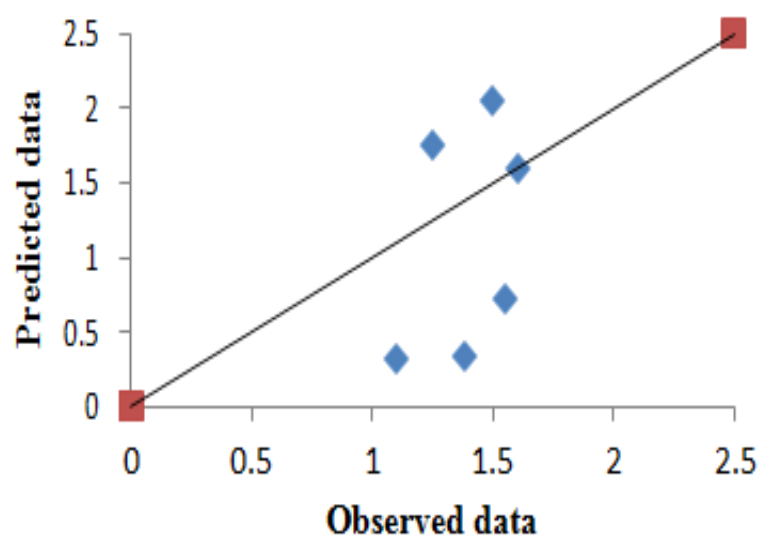

Fig.7(b). Comparison of observed data and predicted data for phosphate after introducing detritus (case study 2)

\section{IV.CONCLUSION}

In this work, ability of Aquatox for predicting lab scale pond ecosystem with limited data is studied. Aquatox predicted results closely correlate with experimental results for the prediction of ammonia and phosphate in the presence of detritus. The introduction of detritus in such an artificial system doesn't represent a true ecosystem prevailing under real time conditions, and as such Aquatox models are reliable only to a certain extent. 
It is suggested that selection of input parameters is most significant part in modeling studies with respect to small lab scale or medium scale studies, and should be done with caution.

\section{ACKNOWLEDGMENT}

The authors sincerely thank Anitha Menon.M for help rendered for experimental studies.

\section{REFERENCES}

1. A.A. Koelmans, A.Vander Heude, L.M.Knijff and R.H.Aalderink, "Integrated modelling of Eutrophication and organic contaminant fate and effects in aquatic ecosystems. A review", Journal of water resources, Vol. 35(15), 2001,pp. 3517-3536.

2. A.Bilaletdin, T. Frisk, V. Podsechin, H. Kaipainen and N. Filatov, "A General Water Protection Plan of Lake Onega in Russia", Water Resource Management, Vol.25, 2011, pp. 2919-2930.

3. E. Morkoc and L. Tolun, "Effects of land-based sources on water quality in the Omerli reservoir (Istanbul, Turkey)", Environ Geology, Vol. 57, 2009, pp. 1035-1045.

4. S.Sourisseau, A. Basse, F.Perie and T.Caquet, "Calibration, Validation and Sensitivity analysis of an ecosystem model applied to artificial streams", Journal of Water research, Vol 42, 2008, pp. 1167-1181.

5. L.Zhang., J.Liu, K.Ho, “ Ecosystem risk assessment modelling method for emerging pollutants", Developments in Environmental Modelling, Vol.7, 2015, pp. 135-162.

6. R.A.Park , J.Clough and M.C.Wellman, "Aquatox modelling environmental fate and ecological effects in aquatic ecosystems", Journal of environmental modeling, Vol. 213, 2008, pp. 1-15.

7. D.Sharma and Arun Kansal, "Assessment of river quality models: a review”, Rev Environ Science Biotechnology, 2012.

8. J. N. Carleton, M. C. Wellman , P. Cocca, A.S. Donigian,R.A. Park, J.T. Love, J.Clough , "Nutrient criteria development with a linked modeling system: methodology development and demonstration", Proceedings of the Water Environment Federation, 2005, pp.1-25.

9. B.Rashleigh, "Assessment of lake ecosystem response to toxic events with the Aquatox model", Water resource management, pp. 291-297, 2007.

10. A.Priya , K. Avishek and G. Pathak, "Assessing the potentials of Lemna minor in the treatment of domestic wastewater at pilot scale", Environmental monitoring assessment, Vol.184, 2012, pp. 4301-4307.

11. W.H. Press, B.P. Flannery, S.A. Teukolsky, and W.T. Vetterling. 1986. Numerical Recipes: The Art of Scientific Computing. Cambridge University Press, Cambridge, $3^{\text {rd }}$ edn, U.K., pp1-1262

\section{AUTHORS PROFILE}

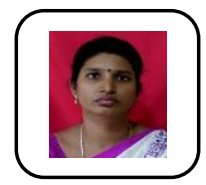

Dr. S.Vanitha has completed her graduation and pos -graduation from Government of College of Engineering, Tirunelveli and Arulmigu Kalasalingam College of Engineering. She has completed her $\mathrm{PhD}$ in Kalasalingam Academy of Research And Education. She has more than 12 years of teaching experience. She has published more than 20 papers in journals and conferences.

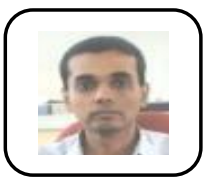

Dr. C.Sivapragasam has completed his graduation and post-graduation from IIT-Roorkee and IIT-Delhi respectively. He completed his $\mathrm{PhD}$ from NUS, Singapore. He has 2 years of industry experience and more than 17 years of teaching experience. He has completed 3 sponsored research projects from various funding agencies and published more than 70 papers in peer reviewed journals and conferences.. 